\title{
Study on Community Cooperation Game of the Main Body in Regional Innovation Ecosystem
}

\author{
Lei Lei1 ${ }^{1,2,3,4}$, Song Wei ${ }^{1}$ \\ ${ }^{1}$ University of Science and Technology of China, Hefei, China \\ ${ }^{2}$ Southwest University of Science and Technology, Mianyang, China \\ ${ }^{3}$ Sichuan Civil-Military Integration Institute, Mianyang, China \\ ${ }^{4}$ Sub-Center of Institute of International Science and Technology Strategy and Policy, Mianyang, China \\ Email: 380083844@qq.com
}

How to cite this paper: Lei, L. and Wei, S. (2017) Study on Community Cooperation Game of the Main Body in Regional Innovation Ecosystem. American Journal of Industrial and Business Management, 7, 1079-1095.

https://doi.org/10.4236/ajibm.2017.79076

Received: September 4, 2017

Accepted: September 22, 2017

Published: September 25, 2017

Copyright $\odot 2017$ by authors and Scientific Research Publishing Inc. This work is licensed under the Creative Commons Attribution International License (CC BY 4.0).

http://creativecommons.org/licenses/by/4.0/

\begin{abstract}
Cooperative innovation of heterogeneous population is more and more important in regional innovation ecosystem, and cross-border cooperation has become one of the effective ways to break through the predicament of ecological niche development. However, the existence of opportunistic behavior will restrain the cooperation motivation among the main communities and threaten the stability of the ecosystem population cooperation network. In order to avoid possible speculation, participants tend to make commitments beforehand. However, how can the commitment effectively avoid partner speculation so as to improve cooperation performance? In this paper, we will study the community game strategy of main body in innovation under multivariate uncertainty, and analyze the impact of commitment on collaborative innovation action.
\end{abstract}

\section{Keywords}

Innovation Ecosystem, Technology Innovation, The Three-Stage Game

\section{Introduction}

At present, with the power of the Internet, industrial production is gradually shifted from centralized control to decentralized control, and the ecosystem collaborative innovation and network manufacturing emerge as a result. Taking advantages of Internet platform's cross time and space, without borders, and promoting sharing characters, the main innovation communities realize integration of resources within and between enterprises, promote the manufacture of innovative products to achieve industrial cooperation, thus witnessing collaborative 
R \& D, crowdsourcing design, supply chain collaboration, cloud manufacturing and other cooperation game. On these bases, this article makes quantitative modeling to cost risk, technical risk and commitment game strategies to investigate the effect of uncertainty on the main body of innovation, pointing out that the condition-dependent commitment is of positive effect in promoting investment and enhancing productivity.

In the regional innovation ecosystem, certain collaborative innovation ecological network will be formed, and the innovation industry chain and value chain alliance will be derived. Because of its complementary resources, cost sharing, risk sharing and synergistic effects [1], technological innovation network has gradually been adopted by more and more enterprises. According to the main body of innovation, innovation network membership can be divided into two categories: one is horizontal cooperation among homogeneous competitors in the same industry; the other is cross industry heterogeneous vertical cooperation. As Geroski [2] puts it, the latter is more common because it can avoid fierce competition and market collusion. For example, the main body of regional innovation community, TOYOTA automobile establishes a close vertical cooperation network [3] with the upstream. In fact, the innovation process in a community formed by main body of innovation within the regional innovation ecosystem is a process of long-term interest game, relationship management and technology evolution. Although the starting point of cooperation is common interests, the risks during innovation may change the original intention, thus one party may take advantage and ignore the partner's interests. In the process of cooperation, there are the risks of uncertain market pricing and manufacturing cost, as well as the risk of technological innovation. Facing the uncertainty of cost and technology, what enterprises can do is to minimize their adverse effects as much as possible. Therefore, it is very necessary to establish a stable and effective prior commitment. The commitment can be expressed in different forms, such as written contracts or informal agreements.

In recent years, research on technology innovation, cooperation and uncertainty in regional innovation ecosystem has emerged gradually both home and abroad. First of all, in vertical cooperation, Harabi [4] analyzes the impact of Regional Innovation Alliance on enterprise innovation. Handfield [5] and others pointed out that industrial chain $\mathrm{R} \& \mathrm{D}$ is of great importance in reducing costs. Chen Yuke [6] and his partners found that upstream participation in innovation can not only improve the member's profit within the alliance, but also is beneficial to the downstream non-member enterprises. Second, new progresses have also been made in the study of uncertainty in innovation. For example, Dixit [7] analyzed the impact of uncertainty on business investment, pointing out that the greater the uncertainty of investment, the smaller the willingness to invest, while Helm and Kloyer [8] have targeted analysis on the transaction risk in upstream and downstream R \& D cooperation. Sun Caihong, Yu Hui and others [9] studied the existence and evolution of opportunism. Brander and Spencer [10] began 
to focus on commitment rather early, and they used definite function relationship to analyze commitment of horizontal joint R \& D. Banerjee and Lin [11] studied the impact of constant price commitments on $\mathrm{R} \& \mathrm{D}$ activities. Sun Guoyan [12] and his partners believe that if manufacturers keep the price flexible and promised price, Internet plus integrated enterprises will invest more in innovation and have higher sales expectation. While Feng Hua [13] and colleagues did enterprise cooperation research, pointing out that if the manufacturer implements transfer pricing commitment strategy, it can make Internet plus integrated enterprises invest more in innovation.

Gilbert, Cvsa (2003) [14] and Kim, Netessine (2013) [15] have studied the topic. But up to now, there is still little research on the commitment game in innovation.

$\mathrm{R} \& \mathrm{D}$ innovation cooperation is a long-term process, although the starting point of cooperation is good, but the market is changing rapidly, and the process of cooperation is susceptible to various factors. With the development of innovation chain and industry chain, $\mathrm{R} \& \mathrm{D}$ cycle will be lengthened accordingly, and its uncertainty will also be enlarged. In recent years, research on innovation, although there are a lot of uncertainty, but the studies on the innovation of community cooperation of the regional innovation ecosystem are still insufficient; especially in the innovation alliance of uncertainty, the existing research results in qualitative, quantitative research is rare, or just for an uncertainty study.

Then, in the face of these uncertain uncertainties, how can we make decisions to ensure the effectiveness of cooperation and safeguard our own interests? This is the focus of this study. Therefore, this study will be the most frequently encountered innovation alliance Regional Innovation Ecosystem in the technical and cost uncertainty quantification study, multivariate decision problems under uncertainty, innovation chain and industrial chain alliance.

\section{The Three-Stage Game Model of Cooperation Innovation}

This paper studies the R \& D cooperation between a manufacturer and an Internet plus integrated enterprise. The manufacturer supply new key components to the Internet plus integrated enterprise, and the enterprise will process the components into products and marketing them. For the sake of generality, we assume that a component corresponds to a new product.

The joint innovation of enterprises and the production and marketing activities after are divided into three stages: the commitment stage of cooperation, the stage of collaborative innovation, and the stage of manufacturing and marketing. The evolution of each stage is shown in Figure 1, where the virtual arrow indicates that the information associated with uncertainty is observed.

The commitment stage, integrated enterprises and manufacturers jointly develop cooperation agreement, determine their investment in innovation, and make commitment on the price of components and the production scale of integrated enterprises (can be controlled by the new product pricing). This is also 


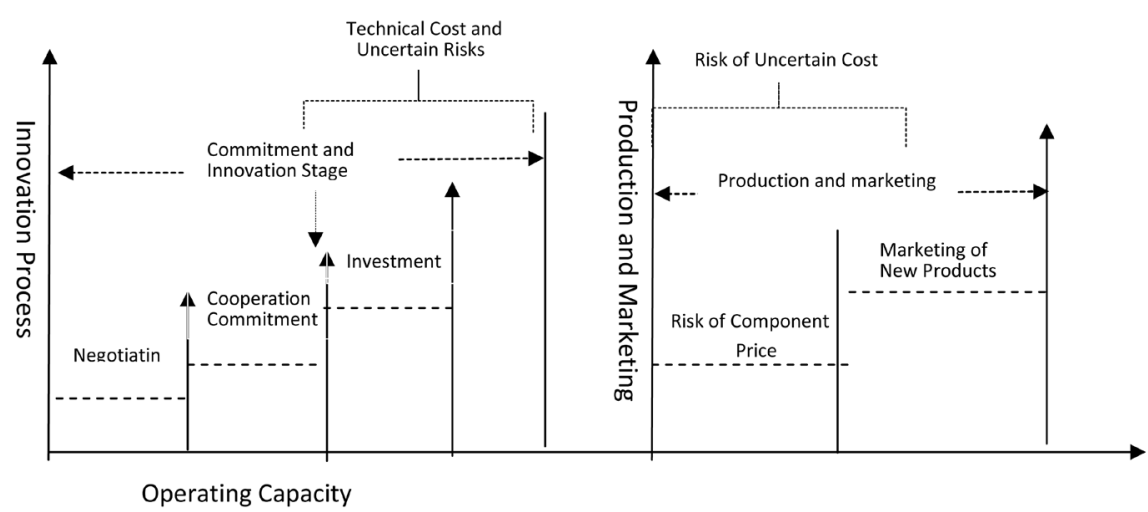

Figure 1. Cooperation Innovation Evolution Diagram of Innovation Community.

the basis for R \& D cooperation. The stage of innovation is the period of innovation investment by enterprises. Inputs can either be tangible or intangible. Finally, it is production and marketing stage. This paper discusses two situations to analyze the compliance and speculation of an enterprise: (1) If there is no prior commitment, the manufacturer can determine the price according to the observed information later; and the Internet plus integrated enterprise may also determine the production decision post the information. (2) If there are credible commitment, manufacturers and the integrated enterprises arrange their production and marketing according to the original commitment. After determining production and marketing strategies, the two sides begin producing, supplying and marketing new products.

Collaborative R \& D based on innovation community shows high uncertainty, and the risk caused by uncertainty is an unavoidable problem in decision-making and management process. This article will discuss the impact of uncertainty of costs and technological innovation capability on collaborative $\mathrm{R} \& \mathrm{D}$. As the process of $\mathrm{R} \& \mathrm{D}$ is often related to the replacement and improvement of raw materials, which directly affect the costs of components, this article only consider that the cost of components is random. Assume that the unit costs of the component and the new product are $\eta$ and $c$ respectively, $\eta$ as the random functions on a given interval, and the expectations and variances are $E \eta=\mu_{1}$, $D \eta=\sigma_{1}^{2}$.

In this paper, Cobb Douglas Production Function is used to describe the synergy of cross-industry resources complementary. Innovation output is affected by three factors, the upstream innovation level $x$, the downstream innovation level $y$ and the joint innovation capability $\theta$ used to characterize technological uncertainty. Suppose that the level of output which is used to measure the size of the potential demand for a new product after the success of innovation is $I=\theta x y, \theta$ is a random variable on a given interval, and $E \theta=\mu_{2}, D \theta=\sigma_{2}^{2}$. And assume that the Internet plus integrated enterprise and the manufacturer's innovation input respectively are $R_{u}=R_{u}(x)$, and $R_{d}=R_{d}(y)$ in the process of cooperation, given that $R_{u}(x)=x^{\alpha}, R_{d}(y)=y^{\beta}$, 
while $\alpha>0, \beta>0$ are the elasticity coefficient of the capital output of $x$ and $y$. In order to make the optimal portfolio in cooperative $\mathrm{R} \& \mathrm{D}$, we need to ensure that the cooperation profit is a concave function about $x$ and $y$, so it is necessary to meet the requirements that $1 / \alpha+1 / \beta<1$. For easier analysis, assume that $\alpha=4, \beta=4$, or $R_{u}(x)=x^{4}, R_{d}(y)=y^{4}$ and the demand function of the new product is

$$
d=\theta x y-\lambda p
$$

In the function, $\lambda$ is a non negative parameter, which represents the ratio of demand in accordance with the price.

\subsection{Action without Commitment}

Non-commitment means the two sides only reached a consensus on cooperation matters and did not specify the orders and prices in the early stage of cooperation. Here the analysis starts from the third stage, using backward induction.

The third stage, which is marketing of new product. Given decision $x, y, w, p$, as well as observed $\eta$ and $\theta$. Among them, $w$ is the price of the new component after innovation, $p$ is the price of the new product. The profit of the Internet plus integrated enterprise and the manufacturer are respectively

$$
\begin{gathered}
\pi_{d}(x, y, w, p \mid \eta, \theta)=(p-w-c) d-y^{4}, \\
\pi_{u}(x, y, w \mid \eta, \theta)=(w-\eta) d-x^{4} .
\end{gathered}
$$

At this stage, Internet plus integrated enterprises control the scale of production through adjusting pricing of new product and maximize profit. The optimal pricing for the integrated enterprise is

$$
p^{*}(x, y, w \mid \eta, \theta)=\frac{\theta x y}{2 \lambda}+\frac{w+c}{2} .
$$

According to Formula (1), $d^{*}(x, y \mid \eta, \theta)=\theta x y-\lambda p^{*}(x, y, w \mid \eta, \theta)$.

The second stage: because the Internet plus integrated enterprise is responsible for marketing new products, so they have more and more accurate assessment to the demand for new products. For simplicity, assume that the enterprise's private information is public knowledge. Then, the manufacturer's expected benefit is

$$
\pi_{u}(x, y, w \mid \eta)=E_{\theta}\left[\pi_{u}(x, y, w \mid \eta, \theta)\right]=\frac{1}{2}(w-\eta)\left(u_{2} x y-\lambda w-\lambda c\right)-x^{4} .
$$

$E_{\theta}[\pi]$ equals to mathematical expectation to $\theta$ from $\pi$. Given that $C=\eta+C, \varphi=\theta x y-\lambda C / \lambda, \quad \bar{C}=E_{\eta}(C)=\mu_{1}+c, \quad \bar{\varphi}_{\theta}=E_{\theta}(\varphi)=\mu_{2} x y-\lambda C / \lambda$, $\bar{\varphi}=E_{\eta}\left(E_{\theta}(\varphi)\right)=\mu_{2} x y-\lambda \bar{C} / \lambda$.

From $\frac{\partial \pi_{u}(x, y, w \mid \eta)}{\partial w}=0$ we can know that $w^{*}(x, y \mid \eta)=\eta+\frac{\bar{\varphi}_{\theta}}{2}$. Thus, the price and demand of the new product are

$$
p^{*}\left(x, y, w^{*} \mid \eta, \theta\right)=C+\frac{\varphi}{2}+\frac{\bar{\varphi}_{\theta}}{4} \text { and } d^{*}(x, y \mid \eta, \theta)=\frac{\lambda \varphi}{2}-\frac{\lambda \bar{\varphi}_{\theta}}{4} .
$$


So, at stage two, the expected profits of the enterprises and the manufacturer are respectively:

$$
\begin{gathered}
\pi_{u}(x, y \mid \eta)=E_{\theta}\left[\left(w^{*}-\eta\right) d^{*}-x^{4}\right]=\frac{\lambda \bar{\varphi}_{\theta}^{2}}{8} x^{4}, \\
\pi_{d}\left(x, y, w^{*} \mid \eta\right)=E_{\theta}\left[\pi_{d}\left(x, y, w^{*} \mid \eta, \theta\right)\right]=\frac{\sigma_{2}^{2} x^{2} y^{2}}{4 \lambda}+\frac{\lambda \bar{\varphi}_{\theta}^{2}}{16}-y^{4} .
\end{gathered}
$$

The first stage, both sides invest in the innovation. Because neither side can accurately predict component costs $\eta$ and joint innovation capability $\theta$ at this stage, profit of the manufacture and the enterprise can be shown as expectations:

$$
\begin{gathered}
\pi_{u}(x, y)=E_{\eta}\left[\pi_{u}(x, y \mid \eta)\right]=\frac{\lambda \bar{\varphi}^{2}}{8}+\frac{\lambda \sigma_{1}^{2}}{16}-x^{4}, \\
\pi_{d}(x, y)=E_{\eta}\left[\pi_{d}(x, y \mid \eta)\right]=\frac{\sigma_{2}^{2} x^{2} y^{2}}{4 \lambda}+\frac{\lambda \bar{\varphi}^{2}}{16}+\frac{\lambda \sigma_{1}^{2}}{16}-y^{4}
\end{gathered}
$$

At this point, both sides form a simultaneous action game, marked as

$$
\left\{\begin{array}{l}
\max _{x} \pi_{u}(x, y), \\
\max _{y} \pi_{d}(x, y) .
\end{array}\right.
$$

Namely, the necessary conditions for the first order existence of equilibrium

$$
\text { are }\left\{\begin{array}{l}
\frac{\mu_{2}^{2} x y^{2}}{4 \lambda}-\frac{\mu_{2} \bar{C} y}{4}-4 x^{3}=0, \\
\frac{\sigma_{2}^{2} y x^{2}}{2 \lambda}+\frac{\mu_{2}^{2} y x^{2}-\mu_{2} \lambda \bar{C} x}{8 \lambda}-4 y^{3}=0 .
\end{array}\right.
$$

Theorem 1 When $\mu_{2}^{4}+4 \mu_{2}^{2} \sigma_{2}^{2}-512 \lambda^{2} \geq 0$, there was a unique and only investment equilibrium under the equilibrium state without commitment and cooperation $\left(x^{*}, y^{*}\right)$.

The proof of Theorem 1 is in Appendix, and the remainder theorem is the same. Theorem 1 shows that when the mean or variance of the joint innovation process of $\theta$ is greater, the possibility of the equilibrium state of the cooperation is greater. If the mean and variance of the joint innovation level are relatively small, like $\mu_{2} \rightarrow 0, \sigma_{2}^{2} \rightarrow 0$, such cooperation will be difficult to achieve a balanced state. If in the preparation of stage of the cooperation, the two sides observed $\mu_{2} \rightarrow 0, \sigma_{2}^{2} \rightarrow 0$, also said the enterprise observed joint cross industry cannot bring the breakthrough on the technology, so the cooperation may not be carried out, there is no sense of cooperation and innovation.

The profit of manufacturer and Internet plus integrated enterprise equilibrium are respectively

$$
\begin{aligned}
& \pi_{u}\left(x^{*}, y^{*}\right)=\frac{\lambda \bar{\varphi}^{*}}{16}\left(\bar{\varphi}^{*}-\bar{C}\right)+\frac{\lambda \sigma_{1}^{2}}{8}, \\
& \pi_{d}\left(x^{*}, y^{*}\right)=\frac{\lambda \bar{\varphi}^{*}}{32}\left(\bar{\varphi}^{*}-\bar{C}\right)+\frac{\sigma_{2}^{2}\left(x^{*} y^{*}\right)^{2}}{8 \lambda}+\frac{\lambda \sigma_{1}^{2}}{16} .
\end{aligned}
$$




\subsection{Main Action under the Commitments}

As the innovation cycle is generally longer and of high uncertainty, the cost of a fixed price commitment is high and the risks great, and the flexibility of innovation chain management is reduced. Therefore, this paper proposes the concept of condition-dependent commitment, that is, the commitment of production and marketing stage depends on the state of innovation stage.

At the beginning of cooperation, the two sides give promise to investment in innovation, while the manufacturer offers price of components to the Internet plus integrated enterprise and the enterprise promises order to manufacturer. Due to the rapidly changing market environment, the cost of the components and the demand for new products in the early stage can not be accurately predicted, and unconditional commitment could not reduce the impact of uncertainty on cooperation and avoid speculation, so condition-dependent commitment mechanism should be considered. It means the both sides first determine innovation investment, on which component price depends, and the production scale of the Internet plus integrated enterprise depends on the upstream price and the innovation investment.

For the two parties cannot observe the following information at the commitment stage, they will have price negotiations. As a result of the influence of the decision state, the quantity of the order $d$ is mainly dependent on $x, y, w$, namely

$$
\tilde{d}(x, y, w)=\arg \max _{d}\left\{E_{\eta}\left[E_{\theta}\left[\pi_{d}(x, y, w, p \mid \eta, \theta)\right]\right]\right\},
$$

While

$$
\tilde{w}(x, y)=\arg \max _{w}\left\{E_{\eta}\left[E_{\theta}\left[\pi_{u}(x, y, w, p \mid \eta, \theta)\right]\right]\right\} .
$$

Therefore, the manufacturer's promised price $\tilde{w}(x, y)=\bar{\varphi} / 2+\mu_{1}$, the Internet plus integrated enterprise's commitment order $\tilde{d}(x, y)=\lambda \bar{\varphi} / 4$, and the equilibrium state of innovation investment is guaranteed by the following theorems.

Theorem 2 When $16 \sqrt{2} \lambda<\mu_{2}^{2}<32 \sqrt{2} \lambda$, the technological innovation cooperation under the condition-dependent commitment would have investment equilibrium $\left(\tilde{x}^{*}, \tilde{y}^{*}, \tilde{w}, \tilde{d}\right)$ and meet the requirement of $\tilde{x}^{*} \tilde{y}^{*}=\mu_{2} \lambda \bar{C} /\left(\mu_{2}^{2}-16 \sqrt{2} \lambda\right)$.

Mark $\tilde{\varphi}^{*}=16 \sqrt{2} \beta \bar{C} /\left(\mu_{2}^{2}-16 \sqrt{2} \lambda\right)$, then $\tilde{\pi}_{u}\left(\tilde{x}^{*}, \tilde{y}^{*}\right)=\lambda \tilde{\varphi}^{*}\left(\tilde{\varphi}^{*}-\bar{C}\right) / 16$, $\tilde{\pi}_{d}\left(\tilde{x}^{*}, \tilde{y}^{*}\right)=\lambda \tilde{\varphi}^{*}\left(\tilde{\varphi}^{*}-\bar{C}\right) / 32$. Compare theorem 1 and 2 , you can see that the condition of reaching equilibrium state with commitment eliminates the influence of innovation level fluctuation, that is to say, commitment reduces the influence of technological innovation uncertainty. The following is further discussion.

Theorem 3 Condition-dependent commitment can help manufacturers increase their innovation inputs $x^{*}<\tilde{x}^{*}$.

Theorem 4 The promotion of condition-dependent commitment to the man- 
ufacturer is bigger than to the Internet plus integrated enterprises in innovation investment, namely $\tilde{x}^{*} / x^{*}>\tilde{y}^{*} / y^{*}$.

The manufacturer, which belongs to the first decision makers in the regional innovation ecosystem, is the direct beneficiary of innovation cooperation for commitment to price and order obviously reduced risks in marketing stage. First of all, the new technology will eventually be used in the new product, and cooperation with the Internet plus integrated enterprise makes manufacturer more clear about demand to components, so manufacturers can communicate with the Internet plus integrated enterprise timely and effectively; secondly, order commitment of component from Internet plus integrated enterprise can also eliminate the manufacturer's pressure on production and sales. Therefore, a reasonable condition-dependent commitment will stimulate the innovation investment of the manufacturer. As for the downstream Internet plus integrated enterprise, on the one hand, in order to profit after the manufacturer, they are more likely to post speculation. The commitment reduced the influence of uncertainty, and eliminated speculative motive to some extent. On the other hand, though the commitment promotes production and marketing of new products, but the marketing risk is not eliminated all together. So the stimulation from $\mathrm{R}$ $\& \mathrm{D}$ cooperation to the Internet plus integrated enterprise on innovation investment is lower than to the manufacturer. Although the upstream commitment reduce the risk of speculative partners to a certain extent, the innovation investment of the Internet plus integration enterprise are more subject to the downstream market demand and new technology changes. Therefore, although the numerical experiments show that most commitments promote the innovation input of the Internet plus integration enterprise, it is not a necessary result. This paper theoretically confirms the importance of manufacturers' participation in collaborative innovation, especially the significant promotion of commitment on manufacturers' innovation investment.

According to the expression (2), the first part of the upstream and downstream profit expression is independent of the variance of the random variable. Therefore, this paper divides the profit without commitment into two parts: one is the average profit which is non speculative profit unrelated to the variance, the other is speculative opportunity profit, related to the fluctuation of random variables. With a commitment, there is no opportunity profit for the speculations of both sides are avoided. If the opportunity profit is not taken into account, the profits of both sides are greater than the average profits without commitment (see the following theorem). But if opportunity profit brought by uncertainty of technology and cost is larger, there may be the case that overall profit of enterprises without commitment is higher than that with one. It won't be the optimal decision for Internet plus integrated enterprises and manufacturers to follow the commitment. This can be concluded to the following theorem.

Theorem 5 Condition-dependent commitment can increase the profits of non-speculative behavior of members in an alliance. 


\section{Numerical Analysis}

In order to understand the above models and conclusions, the corresponding numerical experimental results and the analysis process are listed here. Give parameter $[\lambda, c]=[0.05,0.8]$. In view of the actual limitations, the decision needs to meet following requirements: 1$) d \geq 0$ and $p>C$;2) $\pi_{u}, \pi_{d} \geq 0$. Condition (1) is to ensure that the demand for new product is not negative, and the marginal profit of the new product is above 0 . For it is a market for new product, assume that there is no alternative product on the market. Therefore, the purchase of such products from the market is not considered, that is, the case $d<0$ is not included. Condition 2) is to ensure that the profit of the enterprises is positive. This condition mainly discusses the impact of cost changes on innovation inputs and profits of both sides.

1) Whether condition-dependent commitment or not, the upstream and downstream innovation inputs increase with the growth of production costs. Low cost strategy is the key to win a place in a competitive market. Especially, when the production costs are too high, enterprises will be more willing to reduce costs. If they quantify this intention as innovation investment, we can see that the innovation investment will increase with the growth of production cost.

2) When the mean value and standard deviation are certain, the innovation investment with commitment is higher than that without commitment. This diagram also illustrates that condition-dependent commitment promotes increased innovation inputs from both partners. And with the increase of the cost mean $\mu_{1}$, there is a growing gap between the commitment investment and the investment without.

3) When there is a condition-dependent commitment, the proportion of investment in cooperative $\mathrm{R} \& \mathrm{D}$ is larger than that without commitment. This is also consistent with the condition $\left(\frac{x^{*}}{y^{*}}\right)^{4}<\left(\frac{\tilde{x}^{*}}{\tilde{y}^{*}}\right)^{4}$ shown in Theorem 4 , and the stimulation to upstream innovation input is more effective.

Suppose that the manufacturer's production cost is certain, the change of collaborative innovation effect is related to the mean and variance of joint innovation capability. First, the influence of uncertainty. We can see from Figure 2: (1) For any given $\sigma_{2}$, the output is higher when commitment is given than without. This is due to the condition-dependent commitment, which reduces the risks associated with the uncertainty of joint technological innovation, thus $\mu_{2} x y>\mu_{2} \tilde{x} \tilde{y} ;(2)$ when variance $\sigma_{2}=0$, the technical uncertainty which is similar to the joint innovation, is eliminated. At this point, $x y$ in the two situations are equal. Moreover, when $\sigma_{2}$ increases gradually, the risks of non-commitment grows, and the output decreases. As a result, as the standard deviation increases, output gab between condition-dependent commitment and non-commitment is also enlarging.

We can see from Figure 3, the effect of collaborative innovation varies with the mean cost of manufacturer when there is condition-dependent commitment 


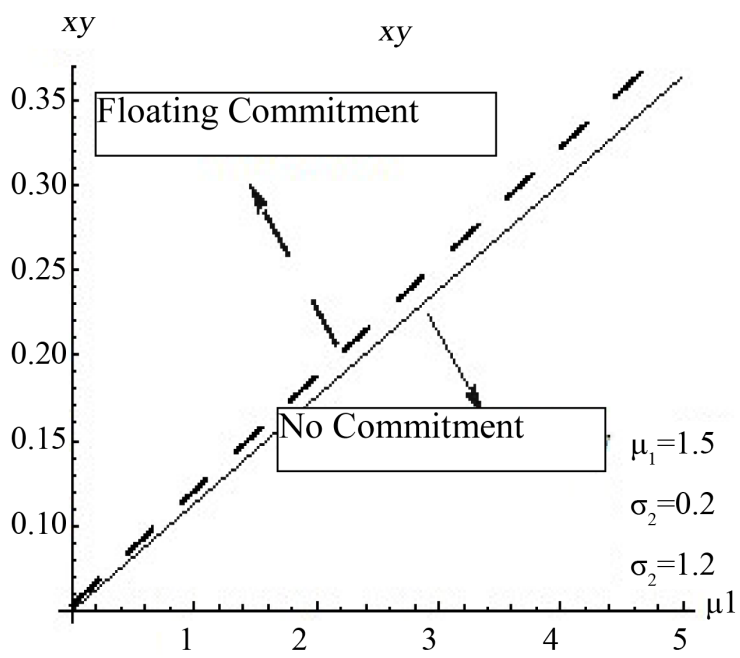

Figure 2. Relation of $x y$ with $\sigma_{2}$.

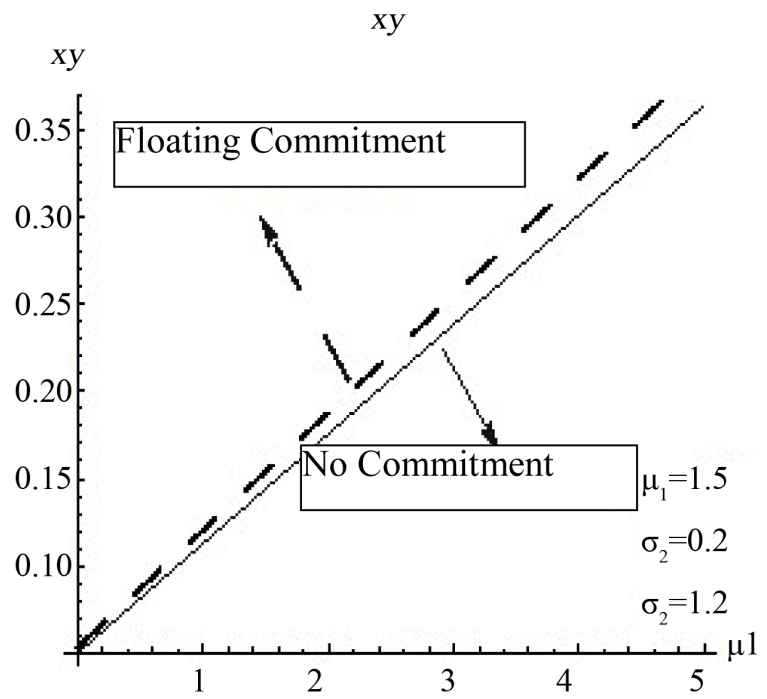

Figure 3. Relation of $x y$ with $\mu_{1}$.

and no commitment. When the joint innovation capability is certain, commitment or not, $x y$ increases with the growth of $\mu_{1}$. At the same time, the upstream and downstream innovation inputs are greater than those without commitment commitments, so the $x y$ with commitment is greater than that without, which means that the output level of condition-dependent commitment is greater too.

We can see from Figure 4, the relationship between $x y$ and $\mu_{2}$. When joint innovation capability is certain, $x y$ with commitment is greater than without, the same with the output. Moreover, if the joint innovation capability of a coalition is stronger, the corresponding innovation investment equilibrium will be less, and the two will be inversely related.

Figure 5 and Figure 6 show upstream and downstream profit with changes of $\mu_{1}$ and $\sigma_{1}$ when there is of or no condition-dependent commitment. As can 


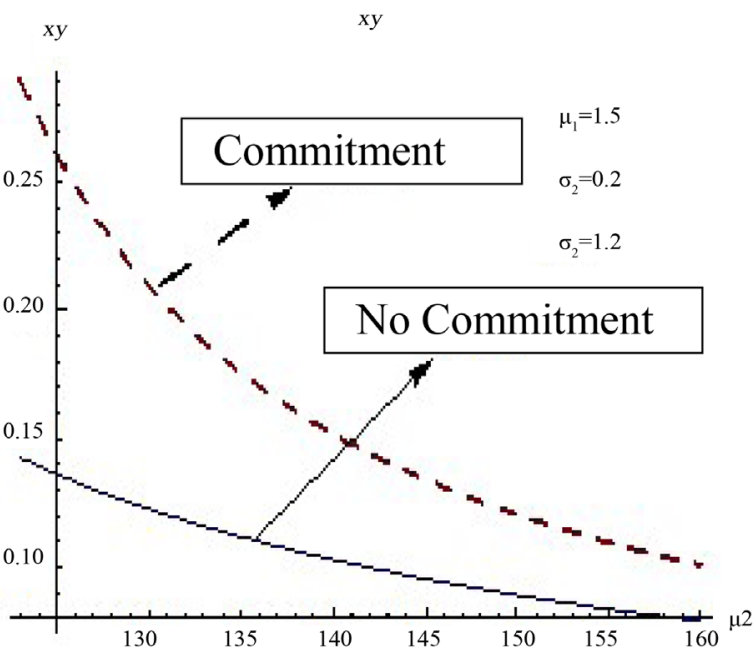

Figure 4. Relation of $x y$ with $\mu_{2}$.

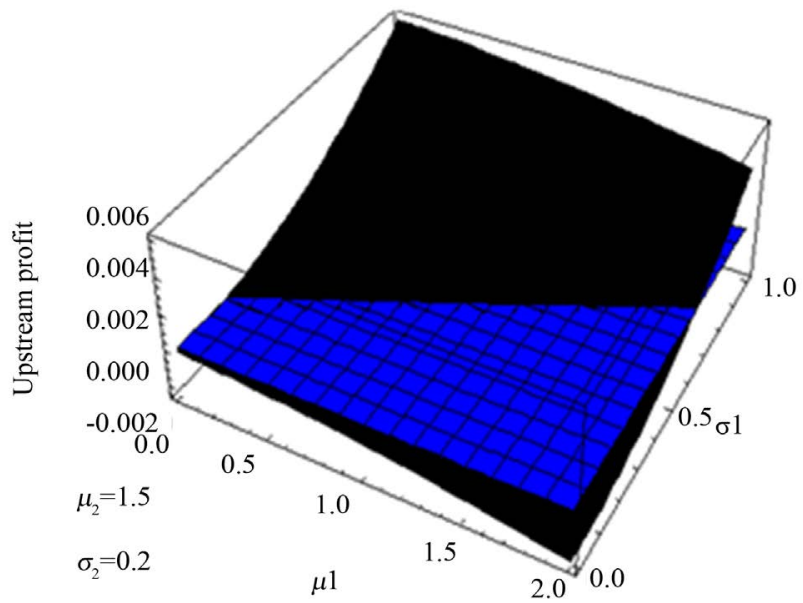

Figure 5. Relation of Manufacture's Profit with $\mu_{1}$ and $\sigma_{1}$.

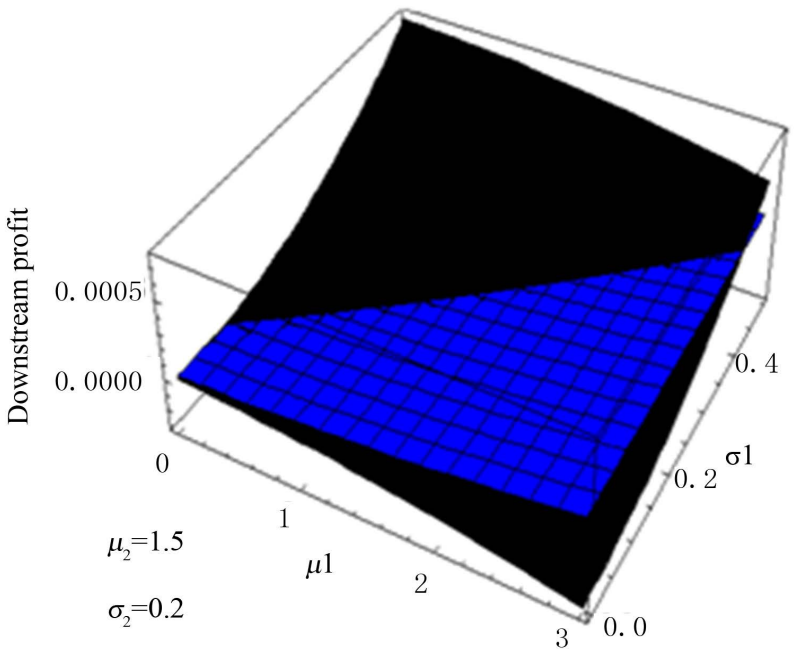

Figure 6. Relation of Integrated Enterprise's Profit with $\mu_{1}$ and $\sigma_{1}$. 
be seen from the diagram, there are three kinds of changes in profits when there is a commitment and no commitment. For manufacturers, for example, if there is an indifferent curve $\sigma_{1}-\gamma_{u} \mu_{1}=\kappa_{u}$ between commitment and non commitment profit $\gamma_{u}, \kappa_{d}$ is a constant and $\gamma_{u}, \kappa_{d}>0$ its value depends on the parameter values in the experiment. Although the profits are the same with or without commitment, the enterprises will choose to keep their promises for honesty and risk's sake. Profits are higher when $\sigma_{1}-\gamma_{u} \mu_{1}<\kappa_{u}$ with commitment. Obviously, the manufacturer will abide by the promise. But when the cost fluctuation is large enough to meet $\sigma_{1}-\gamma_{u} \mu_{1}>\kappa_{u}$, the great opportunity profit brought by non-commitment will exceed the profit without commitment. As a result, manufacturers are more willing to choose non-commitment circumstances.

In Figure 6 there is change of profit for Internet plus integrated enterprise with and without commitment. Similarly, whether the Internet plus integrated enterprises will choose to keep the commitment depends on its profit. Figure 7 shows the indifferent curves for the upstream and downstream profit in the two circumstances. Take the manufacturer for example, in the lower right of the line $\sigma_{1}-\gamma_{u} \mu_{1}=\kappa_{u}$, the firm will choose commitment cooperation; if the profit is on the upper left, the enterprise may break the commitment for interest. A comprehensive analysis of the indifferent curve of upstream and downstream profits will clearly show whether Internet plus integrated enterprise and manufacturers chooses speculation or not during cooperation, and if there is speculation, which party committed it.

We can see from Figure 7, when in $C$ area, both the manufacturer and the Internet plus integrated enterprise have speculation motivation, and the integrated enterprise is even more inclined to non-commitment cooperation. It is also in accordance with the decision-making order in practical cooperation. The integrated enterprise is the subsequent decision-maker, when they find that manufacturer choose speculation, they will not continue to comply with the commitment. In order to ensure their own interests, the integrated enterprise will adjust strategy for maximal interests. And, both parties will benefit from not following

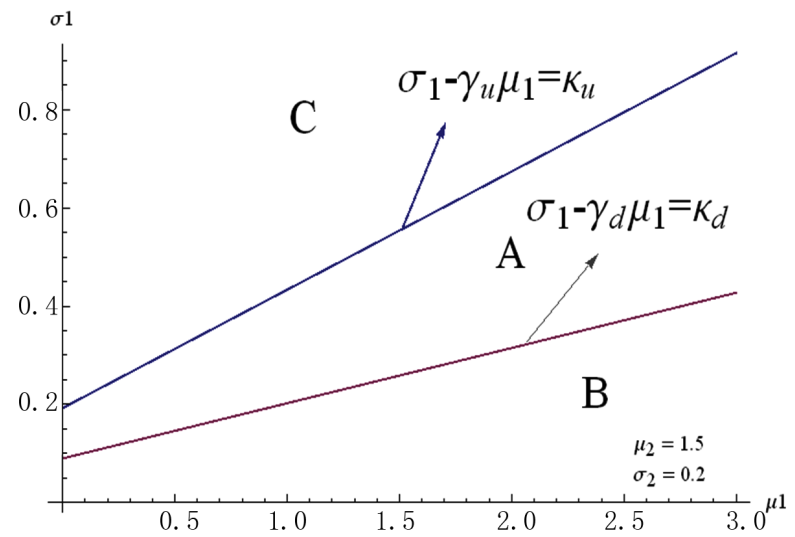

Figure 7. Indifferent Curves for Upstream and Downstream Profit. 
the commitment, and the overall interests of the supply chain will also increase. When the Internet plus integrated enterprise do not have speculative motive, manufacturer often will keep the commitment as shown in the $B$ region. But if cooperation falls in region $A$, the manufacturer will benefit more from commitment cooperation, while the Internet plus integrated enterprise is possible to speculation, and the cooperation will be unstable. If the Internet plus integrated enterprise do not keep the promise, the manufacturer's profit will be damaged.

\section{Conclusions}

Taking regional innovation ecosystem as the background, the Internet plus integrated enterprise and manufacturer collaborative innovation as an example, the article systematically analyzes commitment cooperation and competitive strategy of joint innovation of enterprises when cost and technology are not certain. This paper focuses on the impact of cost uncertainty on technological innovation ecological networks, and proposes the concept of condition-dependent commitment. The study finds that the condition-dependent commitment mechanism is beneficial to promote the innovation input from both sides, and increase the output of cooperative innovation and the interests of both partners.

Although to some extents, commitment can guarantee a long-term and stable cooperation, there is still possible speculation. In order to avoid damage to partner's interests by the other's speculation, and to ensure the credibility of the commitment, effective punishment mechanism should also be included in the commitment. Further discussions are needed in terms of how to set punishment conditions and penalties, and how to compare the effects of different punishment mechanisms under a given mechanism.

In this study, we study the impact of multiple uncertainties on Collaborative Innovation in the context of regional innovation ecosystem. It is found that collaborative innovation can make full use of the competitive advantages of heterogeneous industries, and make full and rational use of resources to coordinate the development of new products. But in the condition of multiple uncertainties, investment equilibrium strategy researches collaborative innovation chain and industrial chain affect the equilibrium conditions of the investment portfolio by demand ratio pricing changes and technological uncertainty.

Finally, it is worth pointing out that there are many uncertainties in the process of collaborative innovation, which only considers the uncertainty of technological risk and cost risk. A series of problems, such as the impact of other uncertainties on innovation cooperation, and the existence of speculative behavior and their impact on partners, remain to be discussed.

\section{Acknowledgements}

The work was supported by the soft science research project of Sichuan science and Technology Department (No. 2016ZR0119). 


\section{References}

[1] Veugelers, R. (1998) Collaboration in R \& D: An Assessment of Theoretical and Empirical Findings. De Economist, 146, 419-443. https://doi.org/10.1023/A:1003243727470

[2] Geroski, P.A. (1995) Markets for Technology: Knowledge, Innovation and Appropriability. In: Stoneman, P., Ed., Handbook of the Economics of Innovation and Technological Change, Blackwell Publishers, Oxford, 90-131.

[3] Jeffrey, K.R. and Thomas, Y.C. (2004) Building Deep Supplier Relationships. Harvard Business Review, 12, 104-114.

[4] Harabi, N. (1998) Innovation through Vertical Relations between Firms, Suppliers and Customers: A Study of German Firms. Industry Innovation, 5, 157-179. https://doi.org/10.1080/13662719800000009

[5] Handfield, R.B., Ragatz, G.L., Petersen, K.J. and Monczka, R.M. (1999) Involving Suppliers in New Product Development. California Management Review, 42, 59-82. https://doi.org/10.2307/41166019

[6] Chen, Y.K., Meng, W.D. and Zou, Y. (2010) Alliance Strategy of Vertical Cooperative Innovation Enterprises under Competitive Conditions. System Engineering Theory and Practice, 30, 857-864.

[7] Dixit, A.K. and Pindyck, R.S. (1994) Investment under Uncertainty. Princeton University Press, Princeton.

[8] Helm, R. and Kloyer, M. (2004) Controlling Contractual Exchange Risks in R \& D Inter-Firm Cooperation: An Empirical Study. Research Policy, 33, 1103-1122. https://doi.org/10.1016/j.respol.2004.05.003

[9] Sun, C.H., Yu, H. and Qi, J.G. (2010) Opportunism Behavior of Resource Input in Enterprise Cooperation R \& D. System Engineering Theory and Practice, 30, 447-455.

[10] Brander, J.A. and Spencer, B.J. (1983) Strategic Commitment with R \& D: The Symmetric Case. Bell Journal of Economics, 14, 225-235. https://doi.org/10.2307/3003549

[11] Banerjee, S. and Lin, P. (2003) Downstream R \& D, Raising Rivals' Costs, and Input Price Contracts. International Journal of Industrial Organization, 21, 79-96. https://doi.org/10.1016/S0167-7187(02)00010-3

[12] Sun, G.Y. and Han, J.J. (2007) The manufacturer price strategystatistics and decision Internet plus incentive integrated enterprise R\&D. Statistics \& Decision, 8 , 150-153.

[13] Feng, H., Ma, S.H. and Cui, Y.F. (2006) Study on the Interaction between Strategic Transfer Pricing, Commitment Strategy and Downstream Innovation. China Management Science, 14, 61-68.

[14] Gilbert, S.M. and Viswanath, C. (2003) Strategic Commitment to Price Stimulates Downstream Innovation in a Supply Chain. European Journal of Operational Research, 150, 617-639.

[15] Kim, S.-H. and Netessine, S. (2013) Collaborative Cost Reduction and Component Procurement under Information Asymmetry. Management Science, 59, 189-206. https://doi.org/10.1287/mnsc.1120.1573 


\section{Appendix}

Theorem 1: by

$$
\left\{\begin{array}{l}
\frac{\partial \pi_{u}(x, y)}{\partial x}=\frac{\mu_{2}^{2} x y^{2}}{4 \lambda}-\frac{\mu_{2} \bar{C} y}{4}-4 x^{3} \\
\frac{\partial \pi_{d}(x, y)}{\partial y}=\frac{\sigma_{2}^{2} y x^{2}}{2 \lambda}+\frac{\mu_{2}^{2} y x^{2}-\mu_{2} \lambda \bar{C} x}{8 \lambda}-4 y^{3} .
\end{array}\right.
$$

So,

$$
\left(\frac{x^{*}}{y^{*}}\right)^{2}=\frac{\sqrt{\sigma_{2}^{4}+128 \lambda^{2}}-\sigma_{2}^{2}}{8 \lambda},
$$

So there,

$$
\left(\mu_{2} x y-\lambda \bar{C}\right)^{2} \mu_{2}+4\left(\mu_{2} x y-\lambda \bar{C}\right) \sigma_{2}^{2} \mu_{2} x y=512 \lambda^{2}(x y)^{2} .
$$

If $\mathrm{x}$ is regarded as an unknown, the upper formula can be solved:

$$
x^{*} y^{*}=\lambda \bar{C} \mu_{2} \frac{\left(\mu_{2}^{2}+2 \sigma_{2}^{2}\right) \pm \sqrt{4 \sigma_{2}^{4}+512 \lambda^{2}}}{\mu_{2}^{4}+4 \mu_{2}^{2} \sigma_{2}^{2}-512 \lambda^{2}} .
$$

But, while $x^{*} y^{*}=\lambda \bar{C} \mu_{2} \frac{\left(\mu_{2}^{2}+2 \sigma_{2}^{2}\right)-\sqrt{4 \sigma_{2}^{4}+512 \lambda^{2}}}{\mu_{2}^{4}+4 \mu_{2}^{2} \sigma_{2}^{2}-512 \lambda^{2}}$, so $\mu_{2} x^{*} y^{*}-\lambda \bar{C}<0$.

But generally speaking, for new technology products, their demand is usually not negative, Therefore $d \geq 0$. Generally the price of new products $p>c$. Therefore, $\mu_{2} x y-\lambda \bar{C}>0$.

$$
x^{*} y^{*} \text { is unique, } x^{*} y^{*}=\lambda \bar{C} \mu_{2} \frac{\left(\mu_{2}^{2}+2 \sigma_{2}^{2}\right)+\sqrt{4 \sigma_{2}^{4}+512 \lambda^{2}}}{\mu_{2}^{4}+4 \mu_{2}^{2} \sigma_{2}^{2}-512 \lambda^{2}} .
$$

Similarly available, $\frac{x^{*}}{y^{*}}$ Also unique, Therefore, while

$$
\begin{array}{r}
x^{*} y^{*} \geq 0, \mu_{2}^{4}+4 \mu_{2}^{2} \sigma_{2}^{2}-512 \lambda^{2} \geq 0 \text {, only } x^{*}, y^{*} \text {. And: } \\
\bar{\varphi}^{*}=\frac{\mu_{2} x^{*} y^{*}-\lambda \bar{C}}{\lambda},
\end{array}
$$

The manufacturer and Internet plus integrated enterprise profit respectively.

$$
\begin{aligned}
& \pi_{u}\left(x^{*}, y^{*}\right)=\frac{\lambda \bar{\varphi}^{*}}{16}\left(\bar{\varphi}^{*}-\bar{C}\right)+\frac{\lambda \sigma_{1}^{2}}{8}, \\
& \pi_{d}\left(x^{*}, y^{*}\right)=\frac{\lambda \bar{\varphi}^{*}}{32}\left(\bar{\varphi}^{*}-\bar{C}\right)+\frac{\sigma_{2}^{2}\left(x^{*} y^{*}\right)^{2}}{8 \lambda}+\frac{\lambda \sigma_{1}^{2}}{16},
\end{aligned}
$$

Theorem 2: The proved that the commitment when manufacturers and Internet plus integrated enterprise profit respectively.

$$
\begin{aligned}
& \tilde{\pi}_{d}(x, y)=\frac{\lambda \bar{\varphi}^{2}}{16}-y^{4}, \\
& \tilde{\pi}_{u}(x, y)=\frac{\lambda \bar{\varphi}^{2}}{8}-x^{4} .
\end{aligned}
$$


The first necessary condition for the existence of equilibrium is:

$$
\left\{\begin{array}{l}
\frac{\partial \tilde{\pi}_{u}(x, y)}{\partial x}=\frac{2 \mu_{2} y\left(\mu_{2} x y-\lambda \bar{C}\right)}{8 \lambda}-4 x^{3}=0 \\
\frac{\partial \tilde{\pi}_{d}(x, y)}{\partial x}=\frac{2 \mu_{2} x\left(\mu_{2} x y-\lambda \bar{C}\right)}{16 \lambda}-4 y^{3}=0 .
\end{array}\right.
$$

So, $\left(\frac{\tilde{x}^{*}}{\tilde{y}^{*}}\right)^{4}=\frac{2}{1}, 16 \sqrt{2} \lambda<\mu_{2}^{2}<32 \sqrt{2} \lambda$, have only $\tilde{x}, \tilde{y}$, and:

$$
\left\{\begin{array}{l}
\tilde{x}=\sqrt[8]{2} \sqrt{\frac{\mu_{2} \lambda \bar{C}}{\mu_{2}^{2}-16 \sqrt{2} \lambda}} \\
\tilde{y}=\frac{1}{\sqrt[8]{2}} \sqrt{\frac{\mu_{2} \lambda \bar{C}}{\mu_{2}^{2}-16 \sqrt{2} \lambda}} .
\end{array}\right.
$$

Therefore, when joint innovation capability meets the conditions $16 \sqrt{2} \lambda<\mu_{2}^{2}<32 \sqrt{2} \lambda$, under the condition dependent commitment, the population cooperative innovation can reach a equilibrium state.

Theorem3: Proof: Just know $x^{*} y^{*}<\tilde{x}^{*} \tilde{y}^{*}$ establish, can launch $\left(x^{*}\right)^{4}<\left(\tilde{x}^{*}\right)^{4}$ is effective.

First prove, $x^{*} y^{*}<\tilde{x}^{*} \tilde{y}^{*}$.

$$
\lambda \bar{C} \mu_{2} \frac{\left(\mu_{2}^{2}+2 \sigma_{2}^{2}\right)+\sqrt{4 \sigma_{2}^{4}+512 \lambda^{2}}}{\mu_{2}^{4}+4 \mu_{2}^{2} \sigma_{2}^{2}-512 \lambda^{2}}<\frac{\mu_{2} \lambda \bar{C}}{\mu_{2}^{2}-16 \sqrt{2} \lambda}
$$

To prove that the formula is established, it is only proof:

$$
\mu_{2}^{2} \frac{\left(\mu_{2}^{2}+2 \sigma_{2}^{2}\right)+2 \sigma_{2}^{2}+16 \sqrt{2} \lambda}{\mu_{2}^{4}+4 \mu_{2}^{2} \sigma_{2}^{2}-512 \lambda^{2}}<\frac{\mu_{2}^{2}}{\mu_{2}^{2}-16 \sqrt{2} \lambda}
$$

Similarly, if inequality (4) is to be proved, need proof

$$
1+\frac{512 \lambda^{2}+16 \sqrt{2} \lambda \mu_{2}^{2}}{\mu_{2}^{4}+4 \mu_{2}^{2} \sigma_{2}^{2}-512 \lambda^{2}}<1+\frac{16 \sqrt{2} \lambda}{\mu_{2}^{2}-16 \sqrt{2} \lambda}
$$

Approximate proof inequality

$$
\frac{\mu_{2}^{2}+16 \sqrt{2} \lambda}{\mu_{2}^{4}+4 \mu_{2}^{2} \sigma_{2}^{2}-512 \lambda^{2}}<\frac{1}{\mu_{2}^{2}-16 \sqrt{2} \lambda}
$$

Obviously, $0<4 \mu_{2}^{2} \sigma_{2}^{2}$, inequality(6) establish. By analogy, inequality (1) Similarly founded. Therefore $x^{*} y^{*}<\tilde{x}^{*} \tilde{y}^{*}$ is effective.

Also due,

$$
\left(x^{*}\right)^{4}=\frac{\mu_{2} x^{*} y^{*}\left(\mu_{2} x^{*} y^{*}-\lambda \bar{C}\right)}{16 \lambda},\left(\tilde{x}^{*}\right)^{4}=\frac{\mu_{2} \tilde{x}^{*} \tilde{y}^{*}\left(\mu_{2} \tilde{x}^{*} \tilde{y}^{*}-\lambda \bar{C}\right)}{16 \lambda},
$$

Because $\mu_{2} x y>2 \lambda \bar{C}$, in this interval, both $\left(x^{*}\right)^{4}$ and $\left(\tilde{x}^{*}\right)^{4}$ are incremented in this interval are increasing.

Therefore $x^{*} y^{*}<\tilde{x}^{*} \tilde{y}^{*}$, so $\left(x^{*}\right)^{4}<\left(\tilde{x}^{*}\right)^{4}$. 
Theorem 4 proved by Theorem 1 and theorem 2

$$
\left(\frac{x^{*}}{y^{*}}\right)^{2}=\frac{\sqrt{\sigma_{2}^{4}+128 \lambda^{2}}-\sigma_{2}^{2}}{8 \lambda},\left(\frac{\tilde{x}^{*}}{\tilde{y}^{*}}\right)^{4}=\frac{2}{1}
$$

So: $\left(\frac{x^{*}}{y^{*}}\right)^{4}<\left(\frac{\tilde{x}^{*}}{\tilde{y}^{*}}\right)^{4}, \frac{\tilde{x}^{*}}{x^{*}}>\frac{\tilde{y}^{*}}{y^{*}}$, proved completed.

Theorem 5 Prove: First, consider the opportunity profit when cooperating

Profit for non speculative parts, $\bar{\varphi}^{*}\left(\bar{\varphi}^{*}-\bar{C}\right)>0$ and $\tilde{\varphi}^{*}\left(\tilde{\varphi}^{*}-\bar{C}\right)>0$, order $f(x y)=\left(\mu_{2} x y-\lambda \bar{C}\right)\left(\mu_{2} x y-2 \lambda \bar{C}\right)$, so $f(x y)>0 \Rightarrow \mu_{2} x y>2 \lambda \bar{C}$.

If order $t=x y$, so $t=x^{*} y^{*}$ and $t=\tilde{x}^{*} \tilde{y}^{*}, \mu_{2} x y>2 \lambda \bar{C}$ is effective. If $t>2 \lambda \bar{C} / \mu_{2}, f^{\prime}(t)>0$, as the $x y$ increases, the function $f$ is incremented.

By theorem3, $x^{*} y^{*}<\tilde{x}^{*} \tilde{y}^{*}$, therefore, state dependent commitments increase the profits of both partners.

\section{Scientific Research Publishing}

Submit or recommend next manuscript to SCIRP and we will provide best service for you:

Accepting pre-submission inquiries through Email, Facebook, LinkedIn, Twitter, etc. A wide selection of journals (inclusive of 9 subjects, more than 200 journals) Providing 24-hour high-quality service User-friendly online submission system Fair and swift peer-review system Efficient typesetting and proofreading procedure Display of the result of downloads and visits, as well as the number of cited articles Maximum dissemination of your research work

Submit your manuscript at: http://papersubmission.scirp.org/ Or contact ajibm@scirp.org 